http://dx.doi.org/10.21721/p2p.2016v3n1.p37-50

INOVAÇÃO

\title{
OCUPAR: ZONAS AUTÔNOMAS TEMPORÁRIAS E PARTILHA DO COMUM
}

\author{
Para os ocupantes do Capanema que, entre Portinaris, sereias e \\ conchas, criaram um mundo-abrigo nos pilotis. Julho de 2016.
}

\section{Ivana Bentes}

Ivana Bentes é professora e pesquisadora da Escola de Comunicação da UFRJ. Foi Secretária de Cidadania e Diversidade Cultural do Ministério da Cultura do Brasil de 2015 até o golpe de maio de 2016.

\begin{abstract}
Resumo
O protagonismo da cultura nas redes de ocupações culturais de resistência ao golpe parlamentar de 2016. Em um contexto de ataque jurídico e político ao campo cultural, que se iniciou com a extinção do Ministério da Cultura, explode um ciclo de ocupações culturais e urbanas de disputa simbólica, no campo das linguagens e do imaginário. As ocupações são o embrião de um movimento político-cultural de novo tipo. A estética da nova política do Brasil que emergiu nesses 13 anos aparece na cena cultural de forma contundente: a cena musical negra, trans, gay, feminina, pop e experimental. A cultura de base comunitária dos Pontos de Cultura, a cultura digital e a cultura de redes, os grupos culturais exige cada vez mais participação nas decisões e na gestão pública.
\end{abstract}

\section{Palavras-chave}

Golpe parlamentar 2016. Pontos de cultura.

\section{OCCUPY: AUTONOMOUS TEMPORARY TERRITORIES AND THE SHARING OF COMMONS}

\begin{abstract}
The role of culture in occupations networks as resistance the parliamentary coup in Brazil, 2016. In the context of a legal and political attack to the cultural field, which began with extinction the Brazilian Ministry of Culture, explodes a cycle of cultural occupations and urban symbolic dispute in the field of language and imagery. The occupations are the embryo of a new type of political and cultural movement. The aesthetics of a new policy of Brazil that emerged in the last 13 years appears in the cultural scene forcefully: the black music scene, trans, gay, female, pop and experimental. The culture based in communities of the Culture Points, digital culture and the culture of networks, cultural groups requires more participation in decision making and public management.
\end{abstract}

Keywords

Parliamentary coup in Brazil, 2016. Culture Points. 


\section{INTRODUÇÃO}

Por que em tempos de guerra, em regimes ditatoriais e na construção de estados de exceção, se censuram e criminalizam artistas, se destroem museus, se pilham obras? Por que é tão importante destruir os objetos da cultura do "inimigo"? E por que é tão decisivo criar contranarrativas que expressam uma reação e resistência?

A lógica da demonização do outro e da doutrina do "choque", em que se tomam medidas radicais de imediato e em curto prazo, para desmobilizar o outro, caracterizam o que podemos nomear de um "semiocídio". Foi o que vimos no Brasil, um ataque aos signos e ao simbólico, com a edição, no primeiro dia de governo, da Medida Provisória de 12 de maio de 2016 assinada pelo presidente interino Michel Temer. Um gesto carregado de violência e que na prática extinguia o Ministério da Cultura ao determinar que a pasta fosse incorporada ao Ministério da Educação.

Era o primeiro dia de instalação do golpe jurídico midiático no Brasil e a medida provisória, em uma só tacada afrontava os sujeitos políticos que emergiram nesses últimos 13 anos no Brasil com a extinção do Ministério da Cultura e extinção do Ministério das Mulheres, da Igualdade Racial, da Juventude e dos Direitos Humanos.

A extinção do MinC, em forma de fusões e reduções, um gesto de violência e afronta, caiu como uma bomba de efeito reverso, e ao invés de intimidar e calar, produziu uma reação negativa e de repúdio imediata nos mais diversos campos e setores da sociedade, com enorme visibilidade midiática.

A reação obrigou, em poucos dias, a publicação de uma nova medida provisória, de 23 de maio de 2016, revogando a extinção/fusão do Ministério da Cultura e descartando a possibilidade se tornar apenas uma Secretaria Nacional de Cultura e restituindo seu estatuto de Ministério.

Neste curto intervalo, o governo interino tentou achar um Secretário Nacional de Cultura e depois um Ministro e recebeu uma dúzia de "nãos" e recusas, principalmente de mulheres, gestoras, professoras, atrizes, personalidades que não aceitaram assumir um cargo em um "machistério", um governo ilegítimo composto primordialmente de homens brancos, ricos e velhos. A escolha do Ministro acabou recaindo no Secretário Municipal de Cultura do Rio de Janeiro, um jovem de 33 anos, Marcelo Caleiro, do PMDB. 


\section{EXTINÇÃO, DESMONTE E INSURGÊNCIA}

Três pontos chamam atenção nessa operação de extinção e ressureição do MinC: o primeiro é o desconhecimento da máquina administrativa, a extinção do MinC paralisou no mesmo dia 12/06 a sua secretaria executiva, o seu financeiro e o seu jurídico, inviabilizando centenas de operações em curso.

Se não fosse revertida, a extinção e depois fusão do MinC com o MEC, significaria de imediato a extinção de centenas de cargos comissionados, o realocamento de servidores do campo cultural para outros órgãos e a paralisia temporária ou inanição de políticas amparadas por Lei, como a Lei Rouanet e a Política Nacional Cultura Viva, políticas de Estado e não de governos.

A extinção do MinC, espinha dorsal de um Sistema Nacional de Cultura complexo e em construção, provocaria um efeito devastador e em cascata da interrupção de políticas públicas no nível nacional, estadual e municipal.

A simples medida provisória da extinção provocou estragos imediatos, por mimetismo: "Prefeitura de Belford Roxo extingue sua Secretaria de Cultura e outras, alinhando-se a Temer".

Eis a tragédia! Para além de uma política nacional centralizada, o MinC incide nas cidades e nos territórios, essa é sua força real e simbólica: a de indução das políticas públicas. Os que ignoravam esse fato não entenderam nada do que os ex-ministros da cultura, Gilberto Gil e Juca Ferreira, propuseram desde 2003, reinventar e re-conceituar o Ministério da Cultura, de baixo para cima.

Fortalecer a rede nacional, induzir a municipalização e territorialização das políticas culturais era o que estávamos fazendo com os Pontos de Cultura, com a retomada da Política Nacional Cultura Viva, na nova gestão de 2015.

Para além de gerir recursos em parceria com os estados e municípios, era decisivo ativar a política de participação (com TEIAS, Fóruns, encontros) ativar a rede capilarizada de fazedores culturais presente nos 26 Estados, no Distrito Federal, em cerca de 1.200 municípios com 80 redes de Pontos de Cultura e uma demanda exponencial de novas redes que tivesse como horizonte chegar as 5.570 cidades do Brasil. 
Sem uma revolução municipalista, sem conectar as bordas em um sistema de co-gestão e participação na cultura, com demandas territoriais, o Estado brasileiro continuará a fazer política cultural de cima para baixo. Fomos interrompidos no meio dessa gestão, com a exoneração do Ministro Juca Ferreira, seus Secretários, dirigentes, gestores, presidentes de vinculadas, colaboradores.

Com ordem e contra ordens, com atos de extinção e remediação, o governo interino mostrava a que veio: destruir o que foi construído, induzir negativamente e desmontar um Sistema Nacional de Cultura que desconhecia, sem força e sem legitimidade para propor nada de novo. Não existe um projeto de Ministério da Cultura no governo interino, as mais de 80 exonerações de cargos comissionados com a saída de profissionais com mais de 30 anos de suas funções não faz sentido que não seja, na impossibilidade de extinguir, promover um silencioso desmonte. Mas cada ação anunciada teve a reação e o repúdio do campo cultural e produziu recuos importantes.

\section{PILHAGEM E REAÇÃO}

O segundo ponto que queremos destacar é a pressa no desmonte seguindo a lógica de um governo ilegítimo, que não sabe quanto tempo dura no mandato, a lógica da pilhagem, da usurpação, da predação.

Lógica também de um presidente interino sem mandato popular, que não tem a legitimidade das urnas, que não é mais elegível (pela lei da ficha limpa) e que não tem nada a perder.

O governo interino, antes do julgamento do impeachment, passou a ser o instrumento de uma transferência forçada e violenta de poder: do grupo legitimamente eleito em 2014 para os perdedores das eleições presidenciais.

O terceiro ponto é o mais revelador. A extinção do MinC e a insurgência do campo cultural contra o golpe, provocou uma reação em série, inesperada e vigorosa e a ocupação sucessiva dos prédios das regionais do MinC por todo o Brasil, as ocupações de prédios públicos e acampamentos em Curitiba, Salvador, nas Funartes de São Paulo, de Minas, do Rio de Janeiro, do Distrito Federal, nas sedes do Iphan, atingindo os 26 estados do Brasil e o DF.

Porque as ocupações são tão importantes? 
As ocupações culturais por todo o Brasil, a insurgência da cultura, com atos protagonizados por artistas e fazedores culturais de todos os campos: Cinema Pela Democracia, Teatro Pela Democracia, Concertos Pela Democracia, Canto da Democracia, atos com blocos de carnaval, Pontos de Cultura, atores e atrizes, dramaturgos, cantores, produtores, uma infinidade de grupos que se entendem como "trabalhadores da cultura" se constituiu como uma importante narrativa contra o governo Temer.

Só comparável em termo simbólico ao próprio reconhecimento do processo de impeachment da presidente Dilma Roussef como um golpe contra a democracia brasileira.

A narrativa do golpe foi vitoriosa em distintos setores da sociedade brasileira que mostraram não haver crime de responsabilidade fiscal nos atos da Presidenta Dilma Rousseff.

A percepção do golpe como forma jurídica de uma violenta transferência de poder foi uma construção coletiva puxada por duas frentes aglutinadores e decisivas: a Frente Brasil Popular e a Frente Povo Sem Medo. Mas podemos nomear uma terceira frente, fluída, transversal, mas igualmente decisiva: a Frente da Diversidade ou Frente da Cultura, oxigenando a militância clássica com novas linguagens do ativismo inspiradas nas expressões culturais.

O processo de criminalização do campo cultural não acabou com a restituição do MinC. Mesmo mantendo o Ministério da Cultura, a mídia e os parlamentares pró impeachment começaram a colocar sob suspeição os seus mecanismos e as ações da gestão anterior.

A Lei Rouanet, que já vinha sendo criticada e reformulada na gestão Juca Ferreira, chegou ao Jornal Nacional em 28/06/2016 em uma operação policial com o nome de "Boca Livre" que fazia eco a uma generalização grosseira do campo conservador que rotula a cultura, os artistas e produtores culturais como os beneficiários de uma "boquinha" ou de benesses estatais.

$\mathrm{Na}$ realidade o que temos, já sabido e denunciado nas gestões anteriores, é uma minoria de produtores, empresas e atravessadores que utilizam a Lei para benefício próprio. Ou empresas que utilizam o recurso público para fazer seu marketing institucional, o que é legal, mas uma distorção que vinha sendo debatida em praça pública na gestão do Ministro Juca Ferreira.

O nome debochado da operação desviava do principal: os 100 maiores beneficiários da Lei Rouanet não são os artistas do campo da esquerda, mas empresas e mais a investigação do seu mal-uso começaram em 2011, foram enviadas para a Controladoria Geral da União (CGU) em 2013 e continuaram na gestão do Ministro Juca Ferreira, gestão abortada pelo governo ilegítimo de Michel Temer. 
O discurso revanchista de parlamentares de uma CPI da Lei Rouanet, respaldado pela Lava Jato e pela mídia caiu no vazio ao acusarem uma suposta "falha de fiscalização do MinC". Ou seja, o governo de Michel Temer é que estaria promovendo um justiçamento no campo cultural. A transformação de um debate público sobre políticas culturais em "caso de polícia” é a forma recorrente do governo interino criminalizar a cultura.

Os maiores beneficiários da Lei Rouanet não são sequer projetos sociais ou artistas "de esquerda", o que começou a aparecer nas investigações, ao contrário, é o mais puro sangue capitalista se valendo do recurso público para fins privados. A CPI foi barrada.

O esforço golpista era que as Leis de Incentivo à cultura passassem a ser vistas como algo escuso, suspeito, impróprio. Criminaliza-se a cultura, mas não se toca nas isenções fiscais para as igrejas, que não pagam imposto, os produtores de fumo, automóveis, bebidas, os próprios jornais e a mídia, beneficiários de verbas publicitárias governamentais.

Mais uma vez estamos falando de semiocídio, o ataque a um campo simbólico: a cultura como fator de desenvolvimento econômico e cidadão transformada em caso de polícia.

\section{O CICLO DAS OCUPAÇÕES}

É nesse contexto de ataque jurídico e político ao campo cultural, que explode o ciclo de ocupações culturais e urbanas de 2016 emergindo na disputa simbólica, no campo das linguagens e do imaginário.

Podemos dizer que as ocupações são o embrião de um movimento político-cultural de novo tipo.

A estética da nova política do Brasil que emergiu nesses 13 anos aparece na cena cultural de forma contundente: a cena musical negra, trans, gay, feminina, pop e experimental. A cultura de base comunitária dos Pontos de Cultura, a cultura digital e a cultura de redes, os grupos culturais exigindo cada vez mais participação nas decisões e na gestão pública.

E o mais decisivo. A mudança de mentalidades e os movimentos sociais produziram estéticas e comportamentos disruptivos que chegaram na política. As ocupações culturais são a face mais visível dessa politização do campo cultural e a culturalização da política. 


\section{DO INVADIR PARA O OCUPAR: UMA VITÓRIA NARRATIVA}

Mas as ocupações têm história, e a mais imediata nos remete a forma como os movimentos sociais, os assentamentos do MST e depois o MTST conseguiram uma vitória política ao reverter o que a mídia e as forças conservadoras rotulavam de "invasão", de terras e de imóveis urbanos, em um movimento de ocupações.

Ocupar é a forma cidadã de narrar uma disputa social e política decisiva: o uso social de terras improdutivas, prédios públicos e privados ociosos, transformados em espaços para a agricultura familiar, moradias e habitações ou simplesmente espaços de convivência e fazimentos. Ocupações reais e simbólicas, ocupação territorial, mas também do imaginário.

Por que ocupar? O Brasil passou 30 anos sem uma política habitacional e com uma Reforma Agrária com avanços e conquistas lentas nos últimos 13 anos, mas o movimento de moradia e os Sem Terra tinham diálogo dentro do governo Lula/Dilma. Programas como o de assentamentos de famílias, o Minha Casa Minha Vida abriram um campo de ampliação e reconhecimento de direitos que se rompe com o governo ilegítimo ao extinguir ou reduzir órgãos, ações e programas que serviam a esses campos.

Ao novo ciclo de ocupações, urbanas e rurais se acrescenta então, para além da disputa material, por terra e casa, uma disputa no campo do imaginário, a disputa cultural.

As ocupações urbanas, nas praças e ruas, ganharam ainda uma projeção global, com os acampa do 15M espanhol, Occupy Wall Street, nos EUA, a ocupação da Praça Tahir, e mais recentemente a Nuit Debut em Paris.

Em 2013 no Brasil tivemos as ocupações das Assembleias Legislativas, Câmara de Deputados, praças e espaços públicos por todo o país.

Tivemos o Ocupa Cabral no Rio, um acampamento na frente do apartamento do então governador Sérgio Cabral, em pleno Leblon. Tivemos as ocupações da Assembleia Legislativa do Espirito Santo, a Ocupa Ales, a Ocupação da Câmara Municipal em Belo Horizonte e da Câmara Municipal dos Vereadores em Porto Alegre ou o caso da Ocupação da Aldeia Maracanã, no Rio de Janeiro, Ocupa Câmara na Cinelândia e tantas outras.

Junho de 2013 também iria inspirar as ocupações secundaristas em 2015 e 2016 nas escolas de todo o Brasil, um movimento impressionante e vigoroso de defesa do ensino público e das escolas feito por estudantes muito jovens. Se a educação foi abandona, se as escolas corriam o 
risco de serem fechadas em São Paulo, são as escolas que precisam ser ocupadas. E os estudantes fizeram mutirões, limparam, arrumaram, cozinharam, ocuparam todas as funções dentro das escolas e produziram uma comunicação comovente de cuidado, afeto, partilha, por um espaço público.

Ocupar para questionar, ocupar para defender, ocupar para protestar, ocupar para construir uma nova forma de gestão vital dos espaços, ocupar o que foi abandonado pelo Estado. As Ocupações são atos de ressignificação.

Também é decisivo chamar atenção para as mudanças de linguagem nas ocupações e protestos de 2013 que inspiraram as ocupações e protestos contra o golpe em 2016. A proposta de abolição de palanque e carros de som nas manifestações, o surgimento dos grupos com seus pequenos megafones, músicas e paródias. Cartazes escritos à mão, colaborativos e singulares, muitos feitos momentos antes, na rua mesmo, as performances artísticas e culturais, as roupas coloridas, a valorização das mídias e redes, uma outra comunicação, não panfletária, mais orgânica e próxima das estéticas dos grupos participantes: afros, indígenas, urbanos. Uma comunicação singularizada.

\section{NOVOS SUJEITOS POLÍTICOS}

Essa estetização e culturalização do político é decisiva para trazer para as Ocupações e para as ruas os chamados "desorganizados". E a cultura se torna decisiva como campo de disputa e renovação. Pois foi na cultura, ao lado das políticas de redistribuição de renda, que se operou uma mudança de mentalidade, onde emergiram outros sujeitos políticos, novos sujeitos do discurso, que ganharam pela primeira vez visibilidade nas políticas culturais do Estado brasileiro.

Se podemos dizer que um movimento como o MST tem no Ministério do Trabalho e do Desenvolvimento Agrário seu lugar de construção e reivindicação de políticas públicas. Se podemos dizer que o Movimento dos Sem Teto (MTST) tem no Programa Minha Casa Minha Vida e no Ministério das Cidades um lugar de construção de disputa e problematização das políticas de moradia.

Podemos afirmar que a cultura das periferias, a cultura indígena, a cultura de base comunitária, os Pontos de Cultura, os terreiros de candomblé, os quilombolas, os novos 
movimentos urbanos, funk, hip hop são os sujeitos culturais que se identificavam com o Ministério da Cultura como como lugar de diálogo e construção de políticas públicas.

\section{DO \#FICAMINC AO \#OCUPAMINC}

Ou seja, a defesa do MinC foi a defesa de um campo de valores, da diversidade cultural, da inclusão subjetiva e nesse sentido uma defesa da radicalização da Democracia. O que ficou claro quando os movimentos de Ocupação que tomaram conta de prédios públicos do MinC nos 27 estados do Brasil permaneceram nas ocupações mesmo depois da restituição do Ministério por Michel Temer.

As ocupações deixaram claro que o que estava em jogo não era apenas o \#FicaMinC, sustentando por alguns grupos de artistas mainstream, mas a defesa da democracia e a destituição do governo ilegítimo, um \#ForaTemer e um \#OcupaTudo.

\section{OS GOLPEADOS}

Quando dizemos: o golpe foi contra a cultura e a cultura é contra o golpe, estamos afirmando que o Brasil experimentou uma mudança de mentalidade em que a cultura foi decisiva para a emergência de novos sujeitos do discurso, visibilizados pelas políticas culturais.

O retrocesso e conservadorismo político, as monoculturas e fundamentalismos _ perseguição a diversidade religiosa; perseguição e racismo diante da cultura de matriz-africana, quilombolas, indígenas, etc. _ atingem a diversidade dos sujeitos culturais.

As consequências são amplas. Estamos falando de repressão as culturas periféricas, culturas LGBTs. A proibição dos bailes funks, o assassinato dos jovens negros nas periferias, a criminalização do hip hop, etc. O Estado pode tanto apoiar políticas mais inclusivas quando induzir a políticas do ódio, ou mais excludentes. 


\section{OS DESORGANIZADOS E OS MOVIMENTOS DE NOVO TIPO}

Quem está nas ocupações? São esses sujeitos diversos e heterogêneos, são esses os sujeitos "golpeados" de forma explícita e que saíram em defesa não de seu setor, mas em defesa da democracia.

Uma novidade nas ocupações, como em junho de 2013, é a chegada dos “desorganizados", sujeitos culturais, que não vem de partidos ou instituições, o precariado e o cognitariado urbanos, os autônomos da cultura, uma nova força política.

Temos ainda que destacar a entrada dos artistas de maior visibilidade no movimento \#FicaMinC e \#VemPraDemocracia. Grupos como a Associação Procure Saber e o Grupo de Ação Parlamentar Pró-Música (GAP) que reúnem artistas estabelecidos, e consagrados. Caetano Veloso, a produtora e empresária Paula Lavigne, entre outros, emprestaram temporariamente sua visibilidade para o movimento em defesa do retorno do MinC e, no Rio de Janeiro, se apresentaram no OcupaMINCRJ.

\section{NÃO VAI TER "LAVAGEM CULTURAL" DO GOLPE!}

Quando o presidente interino Michel Temer recuou e decidiu manter o Ministério da Cultura do Brasil muitos acharam que a decisão iria desmobilizar a cultura. Mas isso não aconteceu, o recuo do Interino Temer na cultura deu inicio a uma reação mais forte em outros campos, diante do desmonte contra os Direitos Humanos, a Previdência, o Ministério do Desenvolvimento Agrário, as Comunicações, a Ciência e Tecnologia etc. Esses 50 anos de retrocesso em pouco mais de 5 dias de gestão.

Uma parte minoritária do campo cultural, que se engajou no movimento \#FicaMinC propôs uma trégua, mas nem os atos da cultura e nem as ocupações arrefeceram, deixando claro que a vitória da ressurreição do Ministério da Cultura não iria estancar os protestos contra o golpe jurídico parlamentar contra a presidenta Dilma Roussef.

Não existe clima de "pacificação" diante de tantos erros grosseiros cometidos com as extinções por Medida Provisória, atos de censura a Comunicação Pública (EBC e TV Brasil), o ataque cognitivo e político, a guerra psíquica e simbólica contra as esquerdas e a democracia. O 
que se ouviu foi: A gente não quer só cultura e nem viver em uma ditadura! O OcupaMinCRJ, os atos e protestos, derivavam para um \#OcupaTudo.

\section{OCUPAR: TECNOLOGIA E DISPOSITIVO DE IMAGINAÇÃO SOCIAL}

O OcupaMInCRJ durou 75 dias no Palácio Gustavo Capanema, no Rio de Janeiro, sede regional do Ministério da Cultura e se tornou uma referência para todas as ocupações do Brasil. Um espaço mágico e uma experiência radical se constituiu ali, nos pilotis modernistas, no mezanino, nas salas e no auditório decorados com painéis de Portinari e azulejos com sereias e conchas, um capítulo histórico das lutas da cultura.

O que aconteceu no OcupaMincRJ foi a demonstração que as ocupações culturais podem se constituir em zonas autônomas temporárias, intervindo diretamente nos espaços públicos, resignificando a arquitetura, transformando as estruturas de concreto em espaços que pulsam.

No dia 16 de maio de 2016, uma centena de artistas, produtores culturais, ativistas, ocuparam o Palácio Capanema para protestar não simplesmente contra o fim do Ministério da Cultura, mas sobretudo pela desocupação do poder do governo interino de Michel Temer.

Muito rapidamente, com grande repercussão e apoio do campo cultural, foi instalado um bunker, um acampamento, um quarto de dormir, uma sala de mídia, uma cozinha coletiva, e no térreo, um palco, espaços para encontros, debates, apresentações teatrais, performances, blocos de carnaval, circo, dança, manifestações indígenas, afro, feministas, festas e protestos.

Decisivo também para o sucesso da Ocupa foi a forte programação de shows, que levaram para o OcupaMinCRJ os Concertos Pela Democracia transformando Carmina Burana em um Fora Temer grandioso e épico; os shows de Caetano Veloso, Erasmo Carlos e Seu Jorge.

E também Frejat, Leoni, Lenini, Jards Macalé, Ava Rocha, bandas experimentais, festas da cidade que se transferiram para os pilotis como a Balck Santa, Wobble, os Escravos da Mauá e tantos outros que colocavam a força da cultura literalmente em ato, emprestando sua estética, suas linguagens, sua credibilidade e capital simbólico para protestar, desconstruir, mas também construir e celebrar a resistência ao golpe.

O OcupaMinCRJ se diferencia por não ser um movimento simplesmente destituinte, mas constituinte. Não ser um movimento simplesmente reativo, mas pro-ativo, não ser um movimento 
tradicional com palavras de ordem, mas com uma multidão de singularidades e subjetividades, constituindo uma ruidocracia.

Rapidamente o OcupaMinCRJ virou um point da cidade, com a chegada de frequentadores de toda a cidade para participar das atividades e atraindo uma grande quantidade de camelôs que se integraram ao pátio do Capanema. Toda uma economia afetiva e vital, todo um ecossistema, uma economia viva produzida pela ocupação.

\section{ECONOMIA VIVA}

Quando custaria ao próprio Ministério da Cultura patrocinar uma ocupação tão rica e diversa? Certamente milhões em cachês, infra-estrutura, comunicação, segurança, uma infinidade de serviços que foram possíveis porque a ocupação era um mutirão, um transbordamento, que se manteve com a colaboração dos próprios frequentadores e mais uma rede de parceiros, apoiadores, simpatizantes, voluntários, ocupantes.

Trata-se de uma experiência radical de economia colaborativa, governança e co-gestão (em nenhum momento as funções administrativas do MinC foram interrompidas!), um "case" de desmonetização das ações culturais. Uma aula de gestão pública!

Evidente que a ocupação passou por todo tipo de desafios também, de um grupo heterogêneo que se conheceu na luta, tendo que se entender, criar códigos comuns, ocupar e urbanizar um espaço em meio de uma reforma e restauração orçada em 20 milhões.

Viver 75 dias dentro e no entorno de um precioso prédio modernista assinado por Le Corbusier, Lúcio Costa e Niemeyer, tendo que zelar por uma joia da arquitetura brasileira e mundial, um marco do uso do concreto e vidro, dormindo entre Portinaris e cuidando para que tudo estivesse simultaneamente em uso e preservado.

Lembro do meu espanto quando cheguei nos primeiros dias para conhecer o OcupaMinCRJ. Controle na entrada, identificação, pulseira no pulso, documentos. Tudo organizado e gerido por cerca de 40 a 70 pessoas acampadas, organizadas em Grupos de Trabalho (GT) que cuidavam da infraestrutura, logística, segurança, jurídico e mais a programação, articulação e comunicação. A participação decisiva, mas discreta e horizontal, de jovens vindos do PCdoB, do PT, do Psol, do Reage, Artista, do Fora do Eixo, da Mídia Ninja, da Frente Brasil Popular, da Frente Povo Sem Medo, dos Pontos de Cultura, grupos que se diluíram e, em meio a 
tantas diferenças, conseguiram estabelecer uma sinergia com os muitos e os desorganizados, a maioria ali.

As plenárias (chamadas planetárias) eram longuíssimas mas extremamente produtivas e inventivas, onde se discutia todas as questões urgentes, da conjuntura política a cozinha, dos comportamentos machistas, a lavagem dos banheiros, das palavras de ordem as novas linguagens. Uma experiência de autoformação intensa, vital, problemática, com todo tipo de questões e arestas.

Tudo ecoava o princípio arquitetônico da integração entre o dentro e o fora, uma arquitetura humana complexa, um espaço urbano vivo, transparente, vazado, aberto ao vento e as ideias fervilhantes que corriam entre os pilotis ainda embrulhados em papelão.

O sucesso do OcupaMinC não o poupou da reintegração de posse violenta e inesperada no dia 25 de julho, com a polícia federal de fuzil e máscara expulsando a todos do prédio. Reintegração que já havia se abatido sobre grande parte das ocupações pelo Brasil e que no Rio de Janeiro ganhavam um sentido de "higienização" política preventiva, tendo em vista a realização das Olimpíadas.

O Ministro interino Marcelo Calero quebrava sua palavra de que não iria pedir reintegração de posse do OcupaMinCRJ, mudava o discurso e acusava as ocupações por "dano ao patrimônio", "impedimento das funções administrativas" e ainda criminalizava os ocupantes acusando de "uso de drogas" e "realização de festas"!

O que nos interessa é que o dispositivo das ocupações veio para ficar como tecnologia social, se constituindo como um dispositivo de ativação dos desejos, de ativação política, constituindo comunidades e redes, deixando emergir movimentos políticos culturalizados. Uma das práticas contemporâneas mais inspiradoras: Ocupa Tudo!

Ocupa a Política, Ocupa o Congresso, Ocupa as Escolas, Ocupa as Praças. Porque é preciso ocupar os espaços públicos, resignificar espaços privados, transformar territórios desvitalizados e privatizados em espaços que pulsam. Ocupa o Imaginário!

O desafio das ocupações é: como criar zonas autônomas temporárias, tempo e espaço? Esse é o dispositivo de luta da cultura: a autogestão dos espaços, a instauração, o processo simultaneamente destituinte e constituinte de uma outra política. 
Quando estava acabando este texto soube do novo destino do OcupaMinCRJ: o Canecão, uma casa de show onde se lê logo na entrada: Aqui se escreve a história da música popular brasileira. Estamos as vésperas dos Jogos Olímpicos, jogos de celebração e exclusão, e em um lugar de visibilidade máxima! O que quer que aconteça sabemos que "Estamos escrevendo a história da democracia brasileira", eis o que importa. Ocupado significa, possuído pelo outro! Longa vida as ocupações.

Ivana Bentes é professora e pesquisadora da Escola de Comunicação da UFRJ. Foi Secretária de Cidadania e Diversidade Cultural do Ministério da Cultura do Brasil de 2015 até o golpe de maio de 2016. 